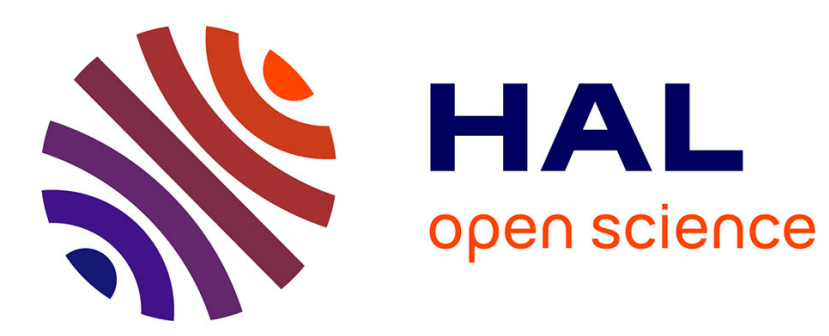

\title{
Modelling of an unconventional airship
}

Saïd Chaabani, Naoufel Azouz, Jean Lerbet, Azgal Abichou

\section{To cite this version:}

Saïd Chaabani, Naoufel Azouz, Jean Lerbet, Azgal Abichou. Modelling of an unconventional airship. 11th ASME Biennial Conference on Engineering Systems Design and Analysis (ESDA2012), Jul 2012, Nantes, France. pp.661-668, 10.1115/ESDA2012-82143 . hal-00764548

\section{HAL Id: hal-00764548 \\ https://hal.science/hal-00764548}

Submitted on 16 Jan 2020

HAL is a multi-disciplinary open access archive for the deposit and dissemination of scientific research documents, whether they are published or not. The documents may come from teaching and research institutions in France or abroad, or from public or private research centers.
L'archive ouverte pluridisciplinaire HAL, est destinée au dépôt et à la diffusion de documents scientifiques de niveau recherche, publiés ou non, émanant des établissements d'enseignement et de recherche français ou étrangers, des laboratoires publics ou privés. 


\title{
MODELLING OF AN UNCONVENTIONAL AIRSHIP
}

\author{
Said CHAABANI*, Naoufel AZOUZ*, Jean LERBET*, Azgal ABICHOU**
}

\author{
* Laboratoire IBISC \\ Université d'Evry Val d'Essonne, \\ 91020 Evry, France \\ e-mail : said.chaabani, naoufel.azouz, \\ jean.lerbet@ibisc.univ-evry.fr
}

\begin{abstract}
This paper presents preliminary results of the modelling of an unconventional unmanned airship moving in an ideal fluid. We are studying here a quad-rotor flying wing.

The airships are also governed by the aerodynamic forces that have to be modelled. An evaluation of the added masses of the airship's components is presented. A first dynamic modelling including the effect of the added masses is proposed.

A control law based on the elaborated dynamic model was applied to this large flying object to evaluate its sensitivity when manoeuvring over an uploading area.
\end{abstract}

\section{INTRODUCTION}

Interest in airships has increased in the last decades. Exhaustive studies in this topic were presented by [12]. Much of the current airships developed and studied in the literature adopt the ellipsoidal shape [46]. This particular shape has a wide popularity in this field due to the existence of a large and reliable knowledge and experimentations for both ellipsoidal airships and their alter ego submarines. However the advances in aerodynamics, control theory and embedded electronics permit to consider new and complex shapes in order to achieve optimal performance for airships. The airship studied here slices with the traditional shapes. The MC 500 is a flying wing (figure 1), developed by the French network DIRISOFT.

The MC500 is an experimental prototype for a set of great, innovating and ecological airships. When used as unmanned aerial vehicles, the large airships need precise dynamic models. This permits to elaborate

\author{
** Lab of mathematical Engineering \\ Polytechnic School, \\ 2070 La Marsa, Tunisia \\ e-mail: azgal.abichou@ept.rnu.tn
}

convenient algorithms of control, stabilization or navigation of these autonomous objects.

To establish the dynamics model, we use a formalism based on the Newton-Euler approach. This choice is mainly motivated by the easiness to build control or stabilization algorithms based on this model. An alternative of this method consists to use a lagrangian approach [6-7].

The MC500 is powered by four electric engines, driving contra-rotating propellers and placed properly to allow good forward propulsion as well as the yaw, pitch and roll control.

Beside, airships are also governed by the aerodynamic forces that have to be modelled. Among the aerodynamic solicitations the added masses phenomenon is one of the most important. In fact, while hovering or in case of low speed displacement, the lift and drag forces and torques could be neglected.

The added masses phenomenon is palpable in the case of objects lighter than air. When an airship moves in an incompressible and infinite inviscid fluid assuming that the external flow is everywhere irrotational and continuous, the kinetic energy of the fluid produces an effect equivalent to an important increase of the mass and of the moments of inertia of the body.

A geometric technique is used for the computation of the different terms of the added mass matrix. A methodology for the computation of generic shapes was presented in [8-9]. The shape of the careen of the MC500 is considered as the combination of a truncated cone with elliptic section and a conoid. Some other assumptions were introduced for the computation of the added masses of the tail fins. An alternative of this computation should be a derivation of this matrix from the velocity potential flow theory [10-11]. When we consider that the velocity potential of the air obeys the Laplace equation, the added 
masses matrix could be determined by resolving this equation, using the sphero-conal coordinates in this case. This leads to the Lamé equations that we solve to retrieve the velocity potential flow. The results of this method will be presented in future works.

In order to validate our model of the airship, we apply a control law on the airship manoeuvring over an uploading area, considered as equilibrium point.

Numerical simulations are presented at the end of this paper. They highlight the developed theoretical results.

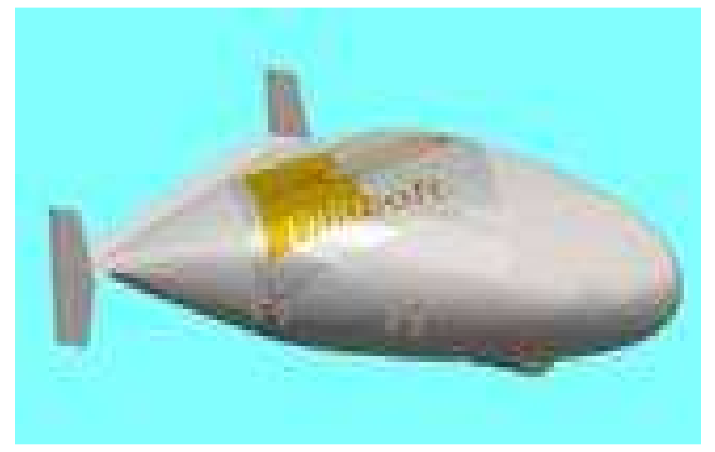

Figure 1. The flying wing Airship MC 500

\section{NOMENCLATURE}

$\eta_{1}=\left[x_{0}, y_{0}, z_{0}\right]^{T}:$ Vector position of the origin expressed in the fixed reference frame $R_{0}$, $\eta_{2}=[\phi, \theta, \psi]^{T}:$ Vector orientation of the pointer $R_{m}$ in regards to $\mathrm{R}$ and given by the Euler angles, $\eta=\left[\eta_{1}, \eta_{2}\right]^{T}:$ Vector attitude compared to $R_{0}$, $\dot{\eta}$ : Velocity Vector compared to $R_{0}$ expressed in $R_{0}$, $v_{1}=[u, v, w]^{T}$ : Velocity Vector expressed in $R_{m}$, $v_{2}=[p, q, r]^{T}:$ Vector of angular velocities expressed in $R_{m}$.

$\mathrm{m}:$ the mass of the airship.

I3 : the identity matrix $3 \times 3$.

\section{DyNAMic ModeL}

\section{II.1. Kinematics}

The MC 500 is modelled in first approximation as a rigid flying object.

In the beginning let us define the different reference frames used in this study (see figure 2). First an earth-fixed frame $R_{0}=\left(O, X_{0}, Y_{0}, Z_{0}\right)$ assumed to be galilean. Then a local reference frame, $R(G, X, Y, Z)$ parallel to the first and fixed at the centre of gravity of the airship G. And finally a third one called pointer $R_{m}=\left(G, X_{m}, Y_{m}, Z_{m}\right)$, its axes are selected as follows:

$X_{m}$ and $Y_{m}$ are the transverse axis of the airship, $Z_{m}$ : the normal axis directed downwards.

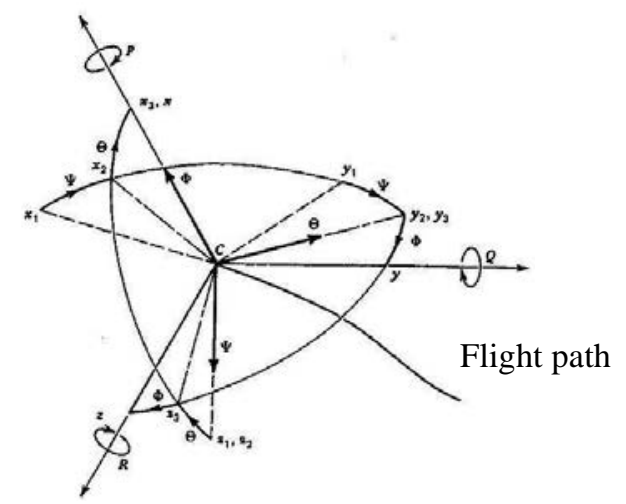

Fig. 2. Different frames used.

Commonly in aeronautics, a parameterization in yaw, pitch and roll is used to describe the orientation of the UAV.

The configuration of the object is described by means of three rotations defined by three angles of orientation i.e. the yaw $\psi$, pitch $\theta$, and roll $\phi$.

The whole transformation between the pointer $R_{m}$ and the local reference frame $\mathrm{R}$ is the combination of elementary matrices of rotation around the three axes $\overrightarrow{\mathrm{z}}, \overrightarrow{\mathrm{y}}_{1}$, and $\overrightarrow{\mathrm{x}}_{2}$, and is given by :

$J_{1}^{\mathrm{T}}\left(\eta_{2}\right)=\left(\begin{array}{ccc}c \theta . c \psi & c \theta . s \psi & -s \theta \\ s \phi . s \theta . c \psi-c \phi . s \psi & \mathrm{s} \phi . s \theta . s \psi+c \phi . c \psi & \mathrm{s} \phi . c \theta \\ c \phi . s \theta . c \psi+s \phi . s \psi & c \phi . s \theta . s \psi-s \phi . c \psi & c \phi . c \theta\end{array}\right)$

Such as: $J_{1}^{T}\left(\eta_{2}\right) . J_{1}\left(\eta_{2}\right)=J_{1}\left(\eta_{2}\right) . J_{1}^{T}\left(\eta_{2}\right)=I_{3}$ We denote by: $\mathrm{c} \theta=\cos \theta ; \mathrm{s} \phi=\sin \phi$

Using the rotation matrix $J_{1}\left(\eta_{2}\right)$, the expression of the linear speed in the reference frame $R_{0}$ is given by:

$$
\dot{\eta}_{1}=J_{1}\left(\eta_{2}\right) \cdot v_{1}
$$

On the other hand, the angular speed of the UAV $v_{2}$ is the combination of the angular speeds around the three axes of yaw, pitch and roll. It can be written related to $\dot{\eta}_{2}$ as:

$$
v_{2}=\left(\begin{array}{l}
p \\
q \\
r
\end{array}\right)=\left(\begin{array}{ccc}
1 & 0 & -\mathrm{s} \theta \\
0 & \mathrm{c} \phi & \mathrm{s} \phi \mathrm{c} \theta \\
0 & -\mathrm{s} \phi & \mathrm{c} \phi \mathrm{c} \theta
\end{array}\right) \cdot\left(\begin{array}{c}
\dot{\phi} \\
\dot{\theta} \\
\dot{\psi}
\end{array}\right)
$$

or :

$$
\dot{\eta}_{2}=J_{2}\left(\eta_{2}\right) \cdot v_{2}
$$

The transformation matrix $J_{2}\left(\eta_{2}\right)$ is represented by: 


$$
J_{2}\left(\eta_{2}\right)=\left(\begin{array}{ccc}
1 & \mathrm{~s} \phi \tan \theta & \mathrm{c} \phi \tan \theta \\
0 & \mathrm{c} \phi & -\mathrm{s} \phi \\
0 & \frac{\mathrm{s} \phi}{\mathrm{c} \theta} & \frac{\mathrm{c} \phi}{\mathrm{c} \theta}
\end{array}\right)
$$

It is noticed that the parameterization by the Euler angles have a singularity in $\theta=\frac{\pi}{2}+k \pi$.

This parameterization is acceptable because it is impossible for an airship to reach this singular orientation of 90 degrees pitching angle.

The global kinematics equation is then:

$$
\dot{\eta}=\left(\begin{array}{cc}
J_{1}\left(\eta_{2}\right) & 0 \\
0 & J_{2}\left(\eta_{2}\right)
\end{array}\right)\left(\begin{array}{l}
v_{1} \\
v_{2}
\end{array}\right)
$$

\section{II.2. Dynamics}

The lighter than air aerial vehicles are subjected to a particular aerodynamic phenomenon called added masses. If a voluminous and light object is moving in an inviscid and incompressible fluid, the kinetic energy of the fluid produces an effect equivalent to an important growing of the mass and inertia of the body. As the airship displays a very large volume, its added masses and inertias become significant. We will assume that the added mass coefficients are constant.

The basis of the analysis of the motion of a rigid body immersed in a perfect fluid is established by Lamb [10]. He proves that the kinetic energy of the fluid surrounding the body can be expressed as a quadratic function of the six components of the translation and rotation velocity.

The whole kinetic energy $\mathrm{T}$ of the rigid body and the surrounding fluid is:

$$
\mathrm{T}=\frac{1}{2} v^{\mathrm{T}} \underbrace{\left(\mathrm{M}_{\mathrm{b}}+\mathrm{M}_{\mathrm{a}}\right)}_{\mathrm{M}} v
$$

Where $\mathrm{M}_{\mathrm{b}}$ is the mass matrix of the body:

$$
\mathrm{M}_{\mathrm{b}}=\left(\begin{array}{cc}
\mathrm{M}_{\mathrm{bTT}} & \mathrm{M}_{\mathrm{bTR}} \\
\mathrm{M}_{\mathrm{bRT}} & \mathrm{M}_{\mathrm{bRR}}
\end{array}\right)=\left(\begin{array}{cccccc}
\mathrm{m} & 0 & 0 & 0 & 0 & 0 \\
0 & \mathrm{~m} & 0 & 0 & 0 & 0 \\
0 & 0 & \mathrm{~m} & 0 & 0 & 0 \\
0 & 0 & 0 & \mathrm{I}_{\mathrm{xx}} & 0 & \mathrm{I}_{\mathrm{xz}} \\
0 & 0 & 0 & 0 & \mathrm{I}_{\mathrm{yy}} & 0 \\
0 & 0 & 0 & \mathrm{I}_{\mathrm{xz}} & 0 & \mathrm{I}_{\mathrm{zz}}
\end{array}\right)(6)
$$

Since the centre of the reference frame coincides with the centre of gravity, the extra-diagonal matrices are null. Taking into account that the plane $\mathrm{x}-\mathrm{z}$ is a plane of symmetry of the MC 500, we conclude that the inertia products $\mathrm{I}_{\mathrm{xy}}$, and $\mathrm{I}_{\mathrm{yz}}$ are null.
Evaluation of the added masses:

The added mass matrix $\mathrm{M}_{\mathrm{a}}$ is also positive definite and symmetric.

$$
\mathrm{M}_{\mathrm{a}}=\left(\begin{array}{ll}
\mathrm{M}_{\mathrm{aTT}} & \mathrm{M}_{\mathrm{aTR}} \\
\mathrm{M}_{\mathrm{aRT}} & \mathrm{M}_{\mathrm{aRR}}
\end{array}\right)
$$

A detailed explanation of its various terms can be found in [12]. Geometric methods could also be used to evaluate these coefficients $[9,10,13,14]$. Following the exhaustive study of Brennen [9], we model our flying wings as a sum of a truncated cone $(\mathrm{T})$ with elliptic section and a conoid (C). This is motivated by the fact that each transverse section of the airship is roughly an ellipse. Two curvatures can be seen in figure 2. That is why we use the theory of the $2 \mathrm{D}$ added masses coefficients to compute the different terms of the added mass matrix.

For example:

$$
\mathrm{M}_{\mathrm{a}_{11}}=\int_{(\mathrm{T})} \mathrm{m}_{11}(\mathrm{y}, \mathrm{z}) \mathrm{dx}+\int_{(\mathrm{C})} \mathrm{m}_{11}(\mathrm{y}, \mathrm{z}) \mathrm{dx}
$$

Where $m_{11}$ is a $2 \mathrm{D}$ added mass coefficient for the forward motion.

Similar procedure is applied on the tail fins.

According to the large difference of size between the diagonal and off-diagonal terms, we will neglect these last terms, keeping only the term $\mathbf{M}_{\mathrm{a} 46}$.

For the computation of the whole dynamics model, we choose to use the Kirchoff's equation [13]:

$$
\begin{aligned}
& \frac{\mathrm{d}}{\mathrm{dt}}\left(\frac{\partial \mathrm{T}}{\partial v_{1}}\right)+v_{2} \wedge \frac{\partial \mathrm{T}}{\partial v_{1}}=\tau_{1} \\
& \frac{\mathrm{d}}{\mathrm{dt}}\left(\frac{\partial \mathrm{T}}{\partial v_{2}}\right)+v_{2} \wedge \frac{\partial \mathrm{T}}{\partial v_{2}}+v_{1} \wedge \frac{\partial \mathrm{T}}{\partial v_{1}}=\tau_{2}
\end{aligned}
$$

$\tau_{1}$ and $\tau_{2}$ are respectively the external forces and torques, including the rotors effects, the weight (m.g), the buoyancy $\mathrm{B}$, and the aerodynamic lift $\left(\mathrm{F}_{\mathrm{L}}\right)$ and $\operatorname{drag}\left(\mathrm{F}_{\mathrm{D}}\right)$.

The dynamical system of the airship becomes:

$$
\left(\begin{array}{cc}
M_{T T} & 0 \\
0 & M_{R R}
\end{array}\right)\left(\begin{array}{l}
\dot{v}_{1} \\
\dot{v}_{2}
\end{array}\right)=\left(\begin{array}{c}
\tau_{1}-v_{2} \wedge\left(M_{T T} v_{1}\right) \\
\tau_{2}-v_{2} \wedge\left(M_{R R} v_{2}\right)-v_{1} \wedge\left(M_{T T} v_{1}\right)
\end{array}\right)
$$

\section{Description of the rotors:}

The MC 500 has four electric engines driving rotors. Each rotor has two parallel contra-rotating propellers to avoid any aerodynamic torque. (Figure 3 ) The rotor can swivel in two directions. A rotation of angle $\beta_{i}$ around the $\mathrm{Y}$ axis $\left(-180^{\circ} \leq \beta_{\mathrm{i}} \leq 180^{\circ}\right)$, and a 
rotation of angle $\gamma_{i}$ around an axis $Z_{i R}$ normal to $Y$ and initially coinciding with the $Z$ axis $\left(-30^{\circ} \leq \gamma_{\mathrm{i}} \leq 30^{\circ}\right)$. A fictive axis $\mathrm{X}_{\mathrm{iR}}$ completes the rotor frame.

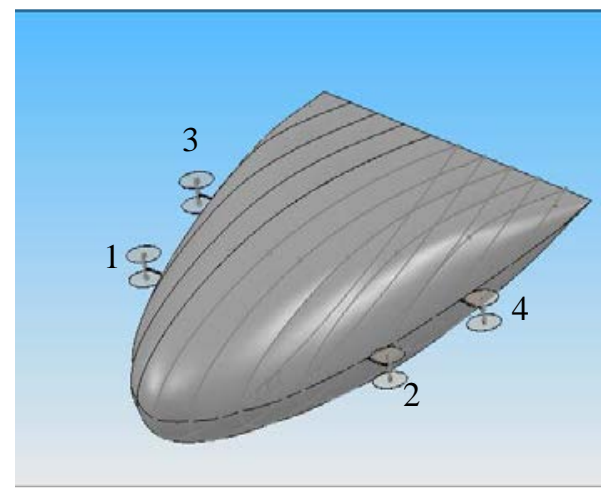

Figure 3. Position of the rotors

An upward motion requires the contribution of the fours rotors in accordance with the configuration of the figure 3. Tilted horizontally, they enable the forward motion. While cruising, the rudders (figure 1) become the main actuators of the tilt, roll or pitch. But when hovering or in the case of low speed flight, the swivelling of the rotors in two directions and the differential change of their rotational speeds are the only way to effect such rotations of the airship or to effect a lateral move.

Let us denote $\mathrm{P}_{\mathrm{i}}$ the position of the rotor $\mathrm{i}$. We can then define a rotation matrix $\mathrm{J}_{3}^{\mathrm{i}}$ between the frame $\left(\mathrm{P}_{\mathrm{i}}, \mathrm{X}_{\mathrm{iR}}, \mathrm{Y}, \mathrm{Z}_{\mathrm{iR}}\right)$ and the pointer $\mathrm{R}_{\mathrm{m}}$ such as:

$$
\mathrm{J}_{3}^{\mathrm{i}}=\left(\begin{array}{ccc}
\mathrm{c} \gamma_{\mathrm{i}} \mathrm{c} \beta_{\mathrm{i}} & -\mathrm{s} \gamma_{\mathrm{i}} \mathrm{c} \beta_{\mathrm{i}} & \mathrm{s} \beta_{\mathrm{i}} \\
\mathrm{s} \gamma_{\mathrm{i}} & \mathrm{c} \gamma_{\mathrm{i}} & 0 \\
-\mathrm{c} \gamma_{\mathrm{i}} \mathrm{s} \beta_{\mathrm{i}} & \mathrm{s} \gamma_{\mathrm{i}} \mathrm{s} \beta_{\mathrm{i}} & \mathrm{c} \beta_{\mathrm{i}}
\end{array}\right)
$$

If we suppose that the intensity of the thrust force of the rotor $\mathrm{i}$ is $\left\|\mathrm{F}_{\mathrm{i}}\right\|$, this force could be introduced in the second member of the dynamic equation as:

$\mathbf{F}_{\mathbf{i}}=\mathrm{J}_{3}^{\mathrm{i}}\left\|\mathrm{F}_{\mathrm{i}}\right\| \cdot \mathrm{e}_{\mathrm{X}_{\mathrm{m}}}$

Where $\mathrm{e}_{\mathrm{X}_{\mathrm{m}}}$ is an unitary vector along the $\mathrm{X}_{\mathrm{m}}$ axis.

The torque produced by this rotor is $\mathbf{F}_{\mathbf{i}} \wedge \mathbf{P}_{\mathbf{i}} \mathbf{G}$

\section{Weight and buoyancy:}

An important characteristic of the airships is the buoyancy $B_{u}$. This force represents a natural static lift, corresponding roughly to $1 \mathrm{Kg}$ for each $\mathrm{m}^{3}$ of helium involved in the careen. We suppose here that this force is applied in the centre of buoyancy B different from the centre of gravity $\mathrm{G}$.

$$
\mathrm{B}_{\mathrm{u}}=\rho_{\mathrm{air}} \cdot \mathrm{V} \cdot \mathrm{g}
$$

where $\mathrm{V}$ is the volume of the careen, $\rho_{\text {air }}$ is the density of the air, and $g$ the gravity.

Let us note $\mathrm{F}_{\mathrm{WB}}$ and $\mathrm{M}_{\mathrm{WB}}$ the force and the moment due to the weight and buoyancy.

We have:

$$
\begin{aligned}
& \mathbf{F}_{\mathbf{W B}}=.\left(\mathrm{mg}-\mathrm{B}_{\mathrm{u}}\right) \cdot \mathrm{J}_{1}^{\mathrm{T}} \mathbf{e}_{\mathbf{Z}} \\
& \mathbf{M}_{\mathbf{W B}}=\mathrm{B}_{\mathrm{u}} \cdot\left(\mathrm{J}_{1}^{\mathrm{T}} \cdot \mathbf{e}_{\mathbf{Z}} \wedge \mathbf{B G}\right)
\end{aligned}
$$

Aerodynamic forces $F_{A}$ :

Such as other flying objects, the airships are subjected to aerodynamic forces. The resultant of these forces could be decomposed into two component forces, one parallel to the direction of the relative wind and opposite to the motion, called Drag, and the other perpendicular to the relative wind, called Lift. The MC500 is designed with an original shape oriented to a best optimization of the ratio lift upon drag forces.

However, and as first study, we try to evaluate the behaviour of the airship in the case of low velocity or while hovering. In these cases, the effect of these forces could be neglected.

The whole system of forces applied on the airship is then:

$$
\tau_{1}=\left(\begin{array}{l}
\sum_{i=1}^{4}\left\|F_{i}\right\| . c \gamma_{i} . c \beta_{i}-\left(m g-B_{u}\right) . s \theta \\
\sum_{i=1}^{4}\left\|F_{i}\right\| s \gamma_{i}+\left(m g-B_{u}\right) . s \phi . c \theta \\
-\sum_{i=1}^{4}\left\|F_{i}\right\| c \gamma_{i} . s \beta_{i}+\left(m g-B_{u}\right) c \phi . c \theta
\end{array}\right)
$$

and :

$$
\tau_{2}=-\left(\begin{array}{l}
\left.c \sum_{i=1}^{4}\left\|F_{i}\right\| . s \gamma_{i}+b_{1}\left\|F_{1}\right\| c \gamma_{1} \cdot s \beta_{1}-\left\|F_{2}\right\| c \gamma_{2} \cdot s \beta_{2}\right) \\
\left.+b_{3}\left\|F_{3}\right\| c \gamma_{3} \cdot s \beta_{3}-\left\|F_{4}\right\| c \gamma_{4} \cdot s \beta_{4}\right)+B_{u} z_{B} \cdot s \phi \cdot c \theta \\
-c \sum_{i=1}^{4}\left\|F_{i}\right\| c \gamma_{i} \cdot c \beta_{i}+a\left(\left\|F_{4}\right\| c \gamma_{4} \cdot s \beta_{4}+\left\|F_{3}\right\| c \gamma_{3} \cdot s \beta_{3}\right. \\
\left.-\left\|F_{1}\right\| c \gamma_{1} \cdot s \beta_{1}-\left\|F_{2}\right\| c \gamma_{2} \cdot s \beta_{2}\right)+B_{u} z_{B} \cdot s \theta \\
b_{1}\left(\left\|F_{1}\right\| c \gamma_{1} \cdot c \beta_{1}-\left\|F_{2}\right\| c \gamma_{2} \cdot c \beta_{2}\right) \\
+b_{3}\left(\left\|F_{3}\right\| c \gamma_{3} \cdot c \beta_{3}-\left\|F_{4}\right\| c \gamma_{4} \cdot c \beta_{4}\right) \\
+a\left(\left\|F_{4}\right\| s \gamma_{4}+\left\|F_{3}\right\| s \gamma_{3}-\left\|F_{1}\right\| s \gamma_{1}-\left\|F_{2}\right\| s \gamma_{2}\right)
\end{array}\right.
$$

The global dynamic system could be expressed in a compact form as follows:

$$
\mathbf{M} . \dot{\mathbf{v}}=\tau+\mathbf{Q}_{\mathbf{G}}
$$


With :

$$
\begin{aligned}
M & =\left(\begin{array}{cc}
M_{T T} & 0 \\
0 & M_{R R}
\end{array}\right), \mathbf{v}=\left(\begin{array}{l}
\boldsymbol{v}_{1} \\
v_{2}
\end{array}\right), \tau=\left(\begin{array}{l}
\tau_{1} \\
\tau_{2}
\end{array}\right) \text { and } \\
\mathbf{Q}_{G} & =\left(\begin{array}{l}
-\mathbf{v}_{2} \wedge\left(M_{T T} \mathbf{v}_{1}\right) \\
-\mathbf{v}_{2} \wedge\left(M_{R R} \mathbf{v}_{2}\right)-\mathbf{v}_{1} \wedge\left(M_{T T} \mathbf{v}_{1}\right)
\end{array}\right)
\end{aligned}
$$

Let us note $\mathrm{M}_{\mathrm{ij}}$ the terms of the whole mass matrix $\mathrm{M}$.

The vector of gyroscopic forces can then be expressed as :

$$
Q_{E}=\left(\begin{array}{l}
M_{22} v r-M_{33} q w \\
M_{33} p w-M_{11} u r \\
M_{11} u q-M_{22} v p \\
-M_{46} p q+\left(M_{55}-M_{66}\right) q r \\
M_{46} p^{2}+\left(M_{66}-M_{44}\right) p r-M_{46} r^{2} \\
\left(M_{44}-M_{55}\right) p q+M_{46} q r
\end{array}\right)
$$

This leads to the developed dynamic model:

$$
\begin{aligned}
& M_{11} \cdot \dot{u}=\sum_{i=1}^{4}\left\|F_{i}\right\| c \gamma_{i} . c \beta_{i}-\left(m g-B_{u}\right) s \theta \\
& -M_{33} q w+M_{22} r v \\
& M_{22} \cdot \dot{v}=\sum_{i=1}^{4}\left\|F_{i}\right\| s \gamma_{i} \cdot+\left(m g-B_{u}\right) s \phi . c \theta \\
& +M_{33} p w-M_{11} r u \\
& M_{33} \cdot \dot{w}=-\sum_{i=1}^{4}\left\|F_{i}\right\| c \gamma_{i} . s \beta_{i}+\left(m g-B_{u}\right) c \phi . c \theta \\
& +M_{11} u q-M_{22} v p \\
& \dot{p}=\frac{1}{\left(M_{44} M_{66}-M_{46}^{2}\right)}\left\{-M_{66} c \sum_{i=1}^{4}\left\|F_{i}\right\| s \gamma_{i}\right. \\
& +\left(M_{46}-M_{66}\right) b_{1}\left(\left\|F_{1}\right\| c \gamma_{1} . s \beta_{1}-\left\|F_{2}\right\| c \gamma_{2} . s \beta_{2}\right) \\
& +\left(M_{46}-M_{66}\right) b_{3}\left(\left\|F_{3}\right\| c \gamma_{3} \cdot s \beta_{3}-\left\|F_{4}\right\| c \gamma_{4} \cdot s \beta_{4}\right) \\
& +M_{46} a\left(\left\|F_{4}\right\| s \gamma_{4}+\left\|F_{3}\right\| s \gamma_{3}-\left\|F_{1}\right\| s \gamma_{1}-\left\|F_{2}\right\| s \gamma_{2}\right) \\
& -M_{66} B_{u} z_{G} s \phi . c \theta-M_{46}\left(M_{44}-M_{55}+M_{66}\right) p q \\
& \left.+\left(M_{55} M_{66}-M_{46}^{2}-M_{66}^{2}\right) q r\right\} \\
& M_{55} . \dot{q}=-c \sum_{i=1}^{4}\left\|F_{i}\right\| c \gamma_{i} \cdot c \beta_{i}+a\left(\left\|F_{4}\right\| c \gamma_{4} . s \beta_{4}\right. \\
& \left.+\left\|F_{3}\right\| c \gamma_{3} . s \beta_{3}-\left\|F_{1}\right\| c \gamma_{1} . s \beta_{1}-\left\|F_{2}\right\| c \gamma_{2} . s \beta_{2}\right) \\
& -B_{u} z_{G} . s \theta+M_{46} p^{2}+\left(M_{66}-M_{44}\right) p r+M_{46} r^{2}
\end{aligned}
$$

$$
\left\{\begin{aligned}
\dot{r} & =\frac{1}{\left(M_{44} M_{66}-M_{46}^{2}\right)}\left\{M_{46} \cdot c \sum_{i=1}^{4}\left\|F_{i}\right\| s \gamma_{i}\right. \\
& +\left(M_{46}-M_{44}\right) b_{1}\left(\left\|F_{1}\right\| c \gamma_{1} \cdot s \beta_{1}-\left\|F_{2}\right\| c \gamma_{2} . s \beta_{2}\right) \\
& +\left(M_{46}-M_{44}\right) b_{3}\left(\left\|F_{3}\right\| c \gamma_{3} . s \beta_{3}-\left\|F_{4}\right\| c \gamma_{4} . s \beta_{4}\right) \\
& -M_{44} a\left(\left\|F_{4}\right\| s \gamma_{4}+\left\|F_{3}\right\| s \gamma_{3}-\left\|F_{1}\right\| s \gamma_{1}-\left\|F_{2}\right\| s \gamma_{2}\right) \\
& +M_{46} B_{u} z_{G} s \phi . c \theta+\left(M_{44}^{2}+M_{46}^{2}-M_{44} M_{55}\right) p q \\
& +M_{46}\left(M_{44}-M_{55}+M_{66}\right) q r
\end{aligned}\right.
$$

\section{Stabilization strategy}

The MC 500 is controlled by varying the speeds of the electric engines, thereby changing the thrust forces $F_{i}$, and by tilting the rotors at angles $\beta_{\mathrm{i}}$ and $\gamma_{\mathrm{i}}$. We propose the following vector for the control of the dirigible:

$$
\left\{\begin{array}{l}
u_{1}=\sum_{i=1}^{4}\left\|F_{i}\right\| c \gamma_{i} \cdot c \beta_{i} \\
u_{2}=\sum_{i=1}^{4}\left\|F_{i}\right\| s \gamma_{i} \\
u_{3}=-\sum_{i=1}^{4}\left\|F_{i}\right\| c \gamma_{i} \cdot s \beta_{i} \\
u_{4}=-M_{66} c \sum_{i=1}^{4}\left\|F_{i}\right\| s \gamma_{i} \\
+\left(M_{46}-M_{66}\right) b_{1}\left(\left\|F_{1}\right\| c \gamma_{1} \cdot s \beta_{1}-\left\|F_{2}\right\| c \gamma_{2} . s \beta_{2}\right) \\
+\left(M_{46}-M_{66}\right) b_{3}\left(\left\|F_{3}\right\| c \gamma_{3} . s \beta_{3}-\left\|F_{4}\right\| c \gamma_{4} \cdot s \beta_{4}\right) \\
+M_{46} a\left(\left\|F_{4}\right\| s \gamma_{4}+\left\|F_{3}\right\| s \gamma_{3}-\left\|F_{1}\right\| s \gamma_{1}-\left\|F_{2}\right\| s \gamma_{2}\right) \\
u_{5}=-c \sum_{i=1}^{4}\left\|F_{i}\right\| c \gamma_{i} \cdot c \beta_{i} \\
+a\left(\left\|F_{4}\right\| c \gamma_{4} \cdot s \beta_{4}+\left\|F_{3}\right\| c \gamma_{3} . s \beta_{3}\right) \\
+a\left(-\left\|F_{1}\right\| c \gamma_{1} \cdot s \beta_{1}-\left\|F_{2}\right\| c \gamma_{2} . s \beta_{2}\right) \\
u_{6}=M_{46} c \sum_{i=1}^{4}\left\|F_{i}\right\| s \gamma_{i} \\
+\left(M_{46}-M_{66}\right) b_{1}\left(\left\|F_{1}\right\| c \gamma_{1} \cdot s \beta_{1}-\left\|F_{2}\right\| c \gamma_{2} . s \beta_{2}\right) \\
+\left(M_{46}-M_{66}\right) b_{3}\left(\left\|F_{3}\right\| c \gamma_{3} . s \beta_{3}-\left\|F_{4}\right\| c \gamma_{4} \cdot s \beta_{4}\right) \\
-M_{44} a\left(\left\|F_{4}\right\| s \gamma_{4}+\left\|F_{3}\right\| s \gamma_{3}-\left\|F_{1}\right\| s \gamma_{1}-\left\|F_{2}\right\| s \gamma_{2}\right)
\end{array}\right.
$$

As first approach the values of the real actuators $\left(\mathrm{F}_{\mathrm{i}}\right.$, $\gamma_{\mathrm{i}}$, and $\beta_{\mathrm{i}}$ ) are computed by the numerical resolution of a rectangular non-linear system.

An alternative to this approach is the use of the real actuators as control vectors. This technique has yet produced convincing results for configuration in degraded mode (the angles gamma are fixed and the 
betas are equal in pairs). However the study of the complete independent system is underway. The results will be published in future works.

Let us consider in this part a small deviation around a position of equilibrium. As our model is local and Eulerian, we will use the theory of small perturbations. This simplified theory gives good results, especially in the stability analysis of the equilibrium states and the response to commands.

\section{III.1. Linearization of equations}

This process begins by decomposing the motion between the equilibrium state and the deviation from this state [15-16]. The idea is to stabilize the XSF around a position of equilibrium defined as follows [17]:

$\mathrm{u}_{\mathrm{d}}=\mathrm{v}_{\mathrm{d}}=\mathrm{w}_{\mathrm{d}}=\mathrm{p}_{\mathrm{d}}=\mathrm{q}_{\mathrm{d}}=\mathrm{r}_{\mathrm{d}}=\theta_{\mathrm{d}}=\phi_{\mathrm{d}}=0$

Where the label $d$ is used for the "desired" parameters.

Under these conditions, and when neglecting the variation of the quadratic terms, and when linearizing the trigonometric expressions [18], the dynamic equations become:

$$
\begin{aligned}
& \left\{\begin{array}{l}
M_{11} \Delta \dot{u}=-\left(m g-B_{u}\right) \Delta \theta+u_{1} \\
M_{22} \Delta \dot{v}=\left(m g-B_{u}\right) \Delta \phi+u_{2} \\
M_{33} \Delta \dot{w}=\left(m g-B_{u}\right)+u_{3}
\end{array}\right. \\
& \left\{\begin{array}{l}
\left(M_{44} M_{66}-M_{46}^{2}\right) \Delta \dot{p}=-M_{66} B_{u} z_{G} \Delta \phi+u_{4} \\
M_{55} \Delta \dot{q}=-B_{u} z_{G} \Delta \theta+u_{5} \\
\left(M_{44} M_{66}-M_{46}^{2}\right) \Delta \dot{r}=M_{46} B_{u} z_{G} \Delta \phi+u_{6}
\end{array}\right.
\end{aligned}
$$

Under the desired conditions (20) we will have:

$$
\begin{aligned}
& \Delta \mathrm{u}=\mathrm{u} ; \Delta \mathrm{v}=\mathrm{v} ; \Delta \mathrm{w}=\mathrm{w} ; \Delta \mathrm{p}=\mathrm{p} ; \Delta \mathrm{q}=\mathrm{q} ; \Delta \mathrm{r}=\mathrm{r} \\
& \Delta \dot{\mathrm{u}}=\dot{\mathrm{u}} ; \Delta \dot{\mathrm{v}}=\dot{\mathrm{v}} ; \Delta \dot{\mathrm{w}}=\dot{\mathrm{w}} ; \Delta \dot{\mathrm{p}}=\dot{\mathrm{p}} ; \Delta \dot{\mathrm{q}}=\dot{\mathrm{q}} ; \Delta \dot{\mathrm{r}}=\dot{\mathrm{r}}
\end{aligned}
$$

and the kinematics part is given by:

$$
\Delta \mathrm{p}=\dot{\phi} ; \quad \Delta \mathrm{q}=\dot{\theta} ; \quad \Delta \mathrm{r}=\dot{\psi}
$$

\section{III.2. Backstepping controller}

Backstepping controllers are especially useful when some states are controlled through other states [19]. Another application for a Quadrotor was proposed by Altug [20] using lagrangian variables.

In this work, we use of the Eulerian variables. These variables are more realistic, because they correspond to the data given by the embedded sensors. We underline that some degrees of freedom such as roll and pitch are particularly critical for the stabilization of the airship when hovering. A blast of wind can destabilize the airship in unloading phase. It is then important to stabilize efficiently these two degrees of freedom.

A strategy of stabilization is summarized in table 1 .

The vector of control is then introduced into the dynamic system. The numerical tests of this command are presented in the following section.

\begin{tabular}{|c|c|c|c|c|c|c|}
\hline 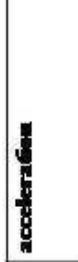 & $\begin{array}{l}3 \\
1 \\
3 \\
3 \\
04 \\
1 \\
11 \\
0\end{array}$ & $\begin{array}{l}3 \\
\lambda^{a} \\
3 \\
y^{4} \\
11 \\
\Rightarrow \\
\Rightarrow\end{array}$ & 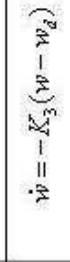 & 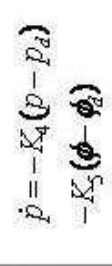 & 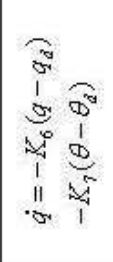 & 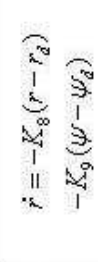 \\
\hline 8 & 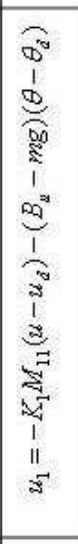 & 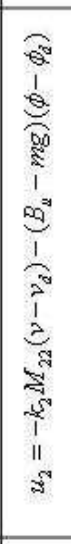 & 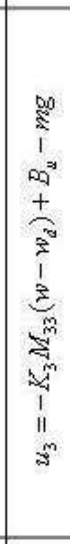 & 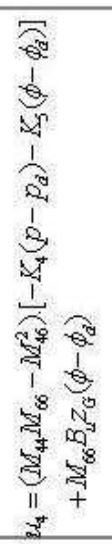 & 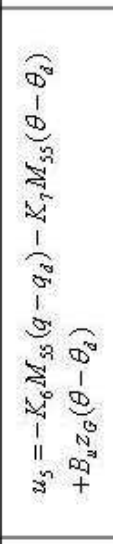 & 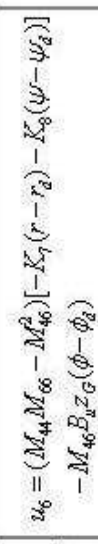 \\
\hline 8 & 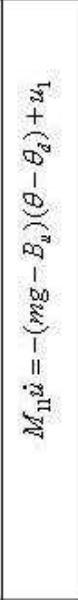 & 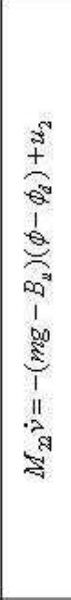 & 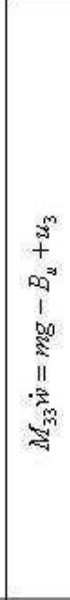 & 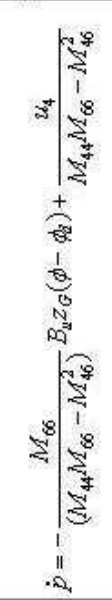 & 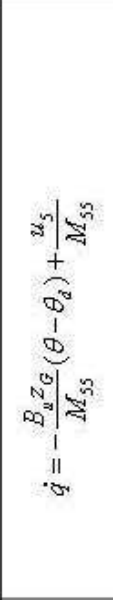 & 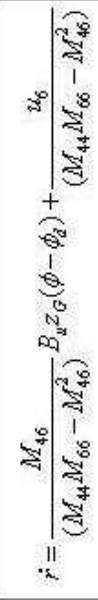 \\
\hline & 量 & 㝵 & 章 & 2 & 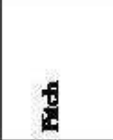 & $\underset{*}{*}$ \\
\hline
\end{tabular}

\section{Numerical simulation}

In this section we present some numerical examples concerning the stabilization of the MC500 around an equilibrium point.

Table 1. Stabilization strategy 
We present here some characteristics of the airship: Geometry:

$\mathrm{z}_{\mathrm{G}}=0.5 \mathrm{~m} \quad ; \mathrm{a}=2.5 \mathrm{~m} ; \mathrm{c}=2 \mathrm{~m} ;$

$\mathrm{b}_{1}=5.4 \mathrm{~m} ; \mathrm{b}_{3}=6.5 \mathrm{~m} ;$ Volume $\mathrm{V}=500 \mathrm{~m}^{3} ;$

Inertia and added mass matrix:

$\mathrm{M}_{11}=; 583 \mathrm{~kg} ; \mathrm{M}_{22}=620 \mathrm{~kg} ; \mathrm{M}_{33}=687 \mathrm{~kg}$;

$\mathrm{M}_{44}=9413 \mathrm{~kg} \cdot \mathrm{m}^{2} ; \mathrm{M}_{55}=10456 \mathrm{~kg} \cdot \mathrm{m}^{2} ;$

$\mathrm{M}_{66}=18700 \mathrm{~kg} \cdot \mathrm{m}^{2} ; \mathrm{M}_{46}=160 \mathrm{~kg} \cdot \mathrm{m}^{2} ;$

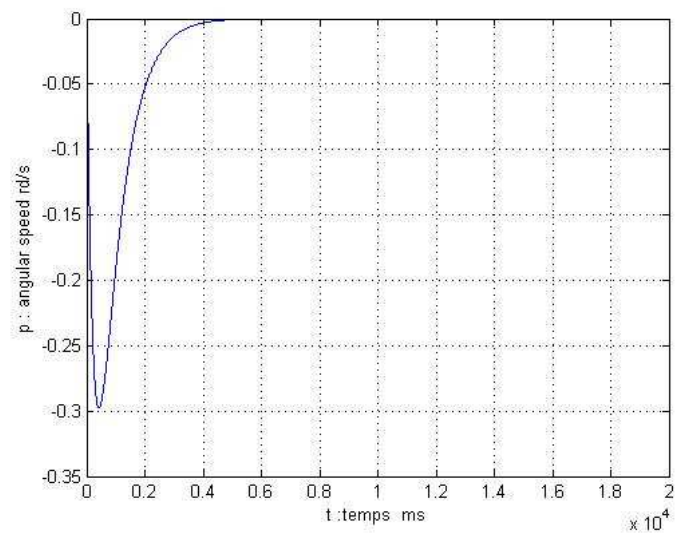

Figure 4. angular rolling speed

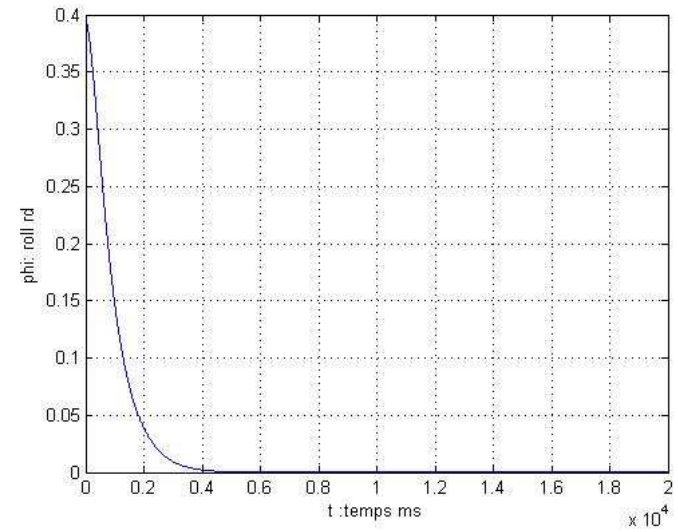

Figure 5. roll angle

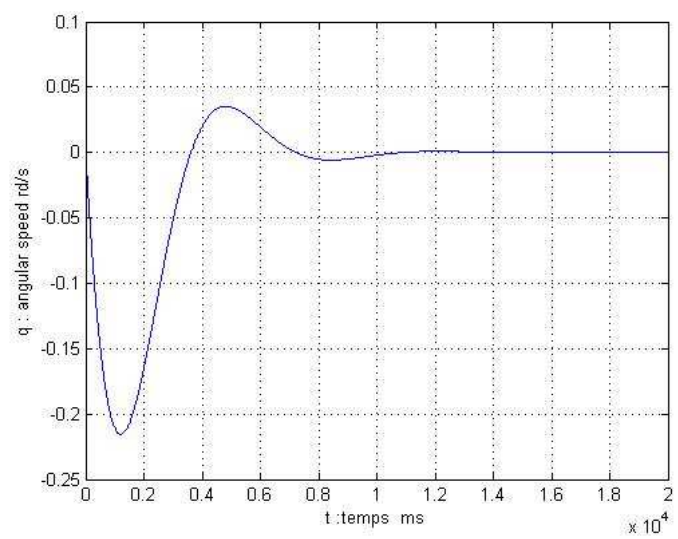

Figure 6. angular pitching angle
As perturbation around the equilibrium point we simulate an initial rolling angle $\Phi=\pi / 8$ and a pitching angle $\theta=\pi / 8$.

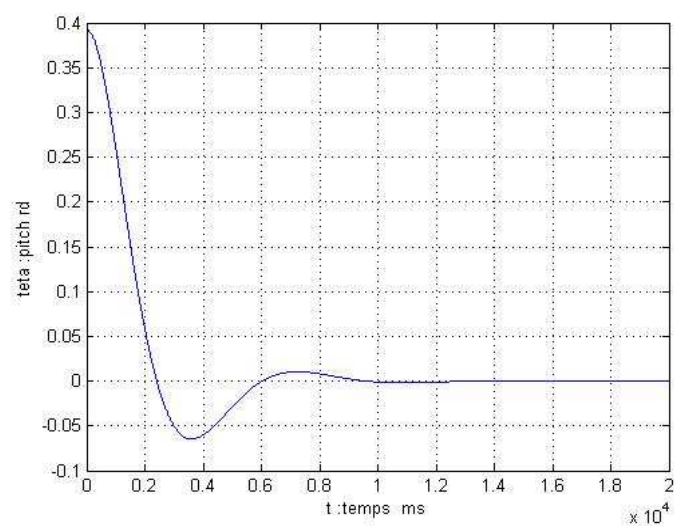

Figure 7. pitch angle

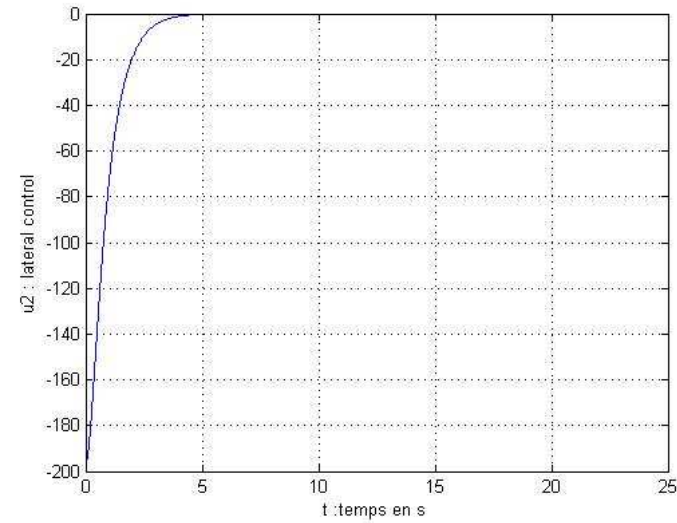

Figure 8. Lateral control

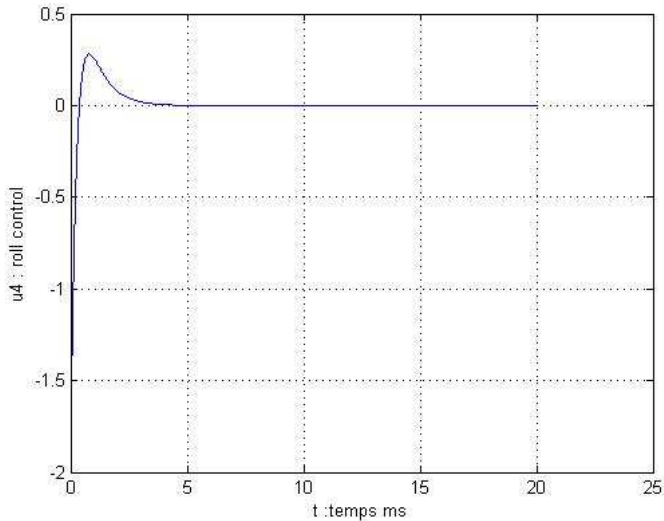

Figure 9. Roll control 


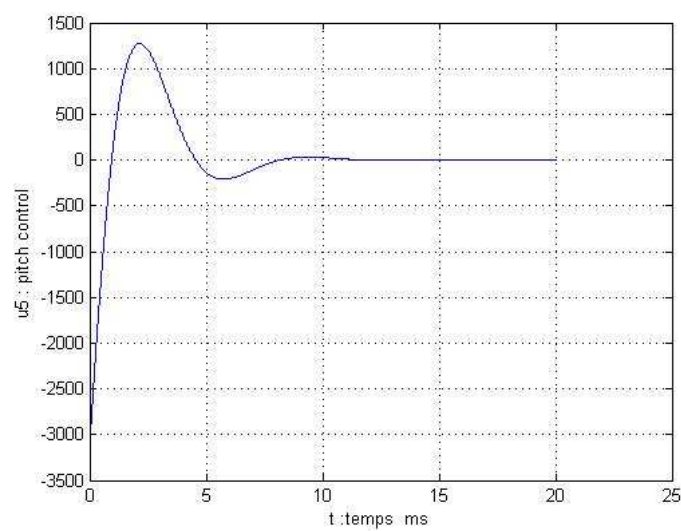

Figure 10. Pitch control

Figures 4-7 depict the convergence of the roll and pitch angles and their derivatives, in a relatively short time. Small values of gains are chosen to avoid a stabilization which may be very costly in energy.

In figures 8-10 we visualized various efficient controls that stabilize in less than six seconds.

Although some aerodynamics terms are roughly estimated and others are neglected, it nonetheless demonstrates the capability of the proposed model to display the behaviour and the sensitivity of this airship around an equilibrium point.

\section{Conclusion}

In this paper a first dynamic model of an unconventional airship is presented. The original shape of the careen induces a necessary reformulation of the dynamic and aerodynamic study of these flying objects. The whole model will be completed by

1) a precise computing of the added masses using the potential flow theory, 2) the introduction of the flexibility of the hull in the global model.

However, the resulting model is a good approach to the problem. The stabilization of the airship at an equilibrium point has been touched on with satisfactory results.

\section{References}

[1] Liao, L., Pasternak, I. , D. (2009)."A review of airship structural research and developments." Prog. Aerosp. Eng. 45 (4-5), pp. 83-96.

[2] Li, Y., Nahon M., SHARF I. , (2011)." Airship Dynamics modeling” Prog. Aerosp. Eng. 27, N³, pp.217-239.

[3] Hygounenc E., Kyun Jung II., Soueres Ph., Lacroix S. (2004) "The Autonomous Blimp Project of LAAS-CNRS: Achievements in Flight
Control and Terrain Mapping". Int. Jour. Robotics Research. Vol. 23, No. 4-5,pp. 473-511.

[4] Jex, H., Gelhausen, P. (1985)."Control response measurements of the Skyship 500 Airship”. Proc. of the $6^{\text {th }}$ AIAA conf. Lighter than air technology, pp. 130-141, NY, USA.

[5] Bessert, N., Frederich, O . (2005)."Nonlinear airship aeroelasticity”. J. Fluid. Struct. 21, pp. 731-742.

[6] El Omari K., Schall, E., Koobus, B., Dervieux, A.(2004) "Inviscid flow calculation around flexible airship.". Mathematical symposium Garcia de Galdeano, 31, pp.(535-544), Spain.

[7] Bennaceur S., Azouz N., Boukraa D. (2006) "An efficient modelling of flexible Airships: Lagrangian approach". Proc. of the ESDA'06 ASME Int. Conf. Torino, Italy.

[8] Korotkin, A . (2009)."Added masses of ship structures". Springer.

[9] Brenner, Ch. (1982)."A review of added mass and fluid inertial forces". Report of the Naval Civil Eng. Lab. CR 82.10, California.

[10] Lamb H., (1945) "On the motion of solids through a liquid. Hydrodynamics", Dover, New York, $6^{\text {th }}$ edition.

[11] Meyerho, W. (1970) "Added masses of thin rectangular plates calculated from potential theory", Jour. Ship Res., vol.14, pp.100-111.

[12] Imlay, F. (1961) "The complete expressions for added mass of a rigid body moving in an ideal fluid”, Report 1528. Hydrodynamics laboratory.

[13] Fossen, T. (1996) "Guidance and control of ocean vehicles" Wiley press.

[14] Munk, M. (1924) "Some tables of the factor of apparent additional mass" NACA, Report N 197.

[15] Degrez , D. (2001)."Performance et Stabilité des Avions". Report of the free University of Bruxelles.

[16] Lewis, A. D. and R. M. Murray, (1997). Configuration controllability of simple mechanical control system. SIAM Journal on Control and Optimization, Vol. 35, N 3.

[17] Khalil, H.K. (1992). Non linear systems, Michigan State University.

[18] Andrea-Novel, B. and Cohen de Lara, M. (1994). Commandes Linéaires des Systèmes Dynamiques. Masson.Paris.

[19] Coron, J-M (1999), On the stabilization of some non linear control system. Kluwer Academic Publishers, Holland, pp.307-367, NATO advanced Study Institute.

[20] Altug, E. (2003). "Vision based control of unmanned aerial vehicles with applications to an autonomous quadrotor." Ph.D. dissertation, faculties of the university of Pennsylvania. 